\title{
Organic Acids, Antioxidants, and Dietary Fiber of Mexican Blackberry (Rubus fruticosus) Residues cv. Tupy
}

\author{
Quinatzin Zafra-Rojas, ${ }^{1}$ Nelly Cruz-Cansino ${ }^{(D)},{ }^{1}$ \\ Alma Delgadillo-Ramírez, ${ }^{1}$ Ernesto Alanís-García, ${ }^{1}$ \\ Javier Añorve-Morga $\left(D,{ }^{2}\right.$ Aurora Quintero-Lira, ${ }^{3}$ \\ Araceli Castañeda-Ovando $\mathbb{D}^{2},{ }^{2}$ and Esther Ramírez-Moreno $\mathbb{D}^{1}$ \\ ${ }^{1}$ Centro de Investigación Interdisciplinario, Área Académica de Nutrición, Instituto de Ciencias de la Salud, \\ Universidad Autónoma del Estado de Hidalgo, Circuito Actopan-Tilcuautla s/n, Ex Hacienda La Concepción, \\ 42160 San Agustín Tlaxiaca, HGO, Mexico \\ ${ }^{2}$ Centro de Investigaciones Químicas, Instituto de Ciencias Básicas e Ingeniería, Universidad Autónoma del Estado de Hidalgo, \\ Centro Universitario, Carretera Pachuca-Tulancingo Km 4.5, 42183 Mineral de la Reforma, HGO, Mexico \\ ${ }^{3}$ Instituto de Ciencias Agropecuarias, Universidad Autónoma del Estado de Hidalgo, Av. Universidad Km 1, Rancho Universitario, \\ 43600 Tulancingo de Bravo, HGO, Mexico \\ Correspondence should be addressed to Esther Ramírez-Moreno; esther_ramirez@uaeh.edu.mx
}

Received 22 November 2017; Revised 2 February 2018; Accepted 20 February 2018; Published 1 April 2018

Academic Editor: Alessandro Attanzio

Copyright (C) 2018 Quinatzin Zafra-Rojas et al. This is an open access article distributed under the Creative Commons Attribution License, which permits unrestricted use, distribution, and reproduction in any medium, provided the original work is properly cited.

\begin{abstract}
Blackberry fruit processing generates residues comprised of peel, seeds, and pulp that are abundant in flavonoids, colorants, and organic acids. The objective of this study was to determine the organic acids, antioxidants, and dietary fiber content of blackberry residues and compare antioxidants and dietary fiber content of a prune-based commercial product. The ABTS, DPPH, and FRAP methodologies were used for antioxidant capacity. The blackberry residues exhibited a high amount of malic acid ( $5706.37 \mathrm{mg} / 100 \mathrm{~g} \mathrm{db})$, phenols (4016.43 mg GAE/100 g db), and anthocyanins content $(364.53 \mathrm{mg} / 100 \mathrm{~g} \mathrm{db})$ compared with the commercial product. These compounds contributed to the antioxidant capacity (by ABTS) of both products but were 20 times higher in blackberry residues. The fruit residues were able to reduce iron (by FRAP) 4.4 times compared to the prune-based product. Total dietary fiber $(44.26 \%)$ and functional properties as water retention capacity $(2.94 \mathrm{~g} / \mathrm{g})$, swelling capacity $(5.00 \mathrm{~mL} / \mathrm{g})$, and fat absorption capacity $(1.98 \mathrm{~mL} / \mathrm{g})$ of blackberry residues were significantly higher than those of the commercial sample. The results demonstrated that, due to its antioxidant compounds and functional properties, the blackberry residue can be considered a source of components with potential benefit to human health.
\end{abstract}

\section{Introduction}

Berries are mainly consumed fresh but are also used to manufacture products such as juices and concentrates [1]. The residues generated after separation of peels, seeds $(4.4 \%$ to $12.2 \%$ ), and pulp are commonly discarded by the industry but still have flavonoids, colorants, pectins, and organic acids [24] that can be used or recovered.

Organic acids and sugars are soluble constituents in berries that are responsible for taste and serve as an index of fruit ripeness; both factors affect consumer acceptability [5].
Previous research has reported that different species of whole berries contain organic acids such as citric, malic, tartaric, fumaric, and shikimic acids in total content ranges of 21.5 to $235 \mathrm{mmol} / \mathrm{kg}$, specifically of $45.1 \mathrm{mmol} / \mathrm{kg}$ for the fruticosus species [6]. Published literature about the content of these individual compounds in blackberry (Rubus fruticosus) residues was not found.

Blackberry (Rubus fruticosus) fruits also contain phenolic compounds as anthocyanins, flavonols, chlorogenic acid, and procyanidins, which can have beneficial effects on human health [7]. Phenols are considered compounds with potent 
antioxidant and free-radical scavenging properties that protect important biomolecules against oxidative damage [8]. Several studies have evaluated these compounds in blackberries (Rubus) of different species and varieties ( $R$. sp. hyb Marion, $R$. laciniatus Evergreen, $R$. spp. Tupy, and $R$. fruticosus) as a whole fruit and in pulp or seeds, including the use of several extraction technologies (supercritical carbon dioxide extraction, ultrasound assisted extraction, pressurized liquid extraction, etc.) to recover phenols, anthocyanins, fatty acids, phytosterols, and tocopherols, compounds responsible for antioxidant activity [9-14]. Fewer studies have been performed on the evaluation of antioxidants in the bagasse or residues generated by the blackberry fruit processing [11, $13,15]$. Phenolic compounds and dietary fiber are generally studied separately, probably because of the differences in their chemical structures, physicochemical and biological properties, and metabolic pathways [16]. However, these are plant food constituents that are associated with many health benefits and have been demonstrated to reduce the risk of developing cancer and some chronic diseases [17, 18]. Dietary fiber has an essential role in intestinal health and appears to be significantly associated with a reduction of cholesterolemia and modification of the glycemic response [19].

Considering that most studies evaluate the whole fruit but not the residues that may have a great potential as a source of bioactive compounds (dietary fiber, antioxidants, fatty acids, etc.), the objective of this study was to determine the organic acids, antioxidants, and dietary fiber content of blackberry (Rubus fruticosus) cv. Tupy residues (comprised of seeds, peel, and pulp) and compare antioxidants and dietary fiber values with a commercial product.

\section{Materials and Methods}

2.1. Sample Preparation. Blackberries (Rubus fruticosus cv. Tupy) were collected from Atotonilco, Hidalgo, Mexico, in January 2016. Fruits without external injuries were selected and washed. Blackberries were processed into juice and the resulting residues (seeds, peel, and pulp) were collected as follows: fruit was stirred using an industrial blender (38BL52 LBC10, Waring Commercial, Torrington, CT, USA) and then passed through a conventional strainer; the retained bagasse (seeds and peel) was collected and mixed with the pulp (precipitate) obtained after juice was clarified by centrifugation (Allegra 25 ${ }^{\mathrm{TM}}$, Beckman Coulter, Palo Alto, CA, USA) at $15,300 \mathrm{~g}$ for $30 \mathrm{~min}$ at $4^{\circ} \mathrm{C}$. All blackberry residues (BR) (bagasse plus pulp) were lyophilized (7753020, Labconco, Kansas City, MO, USA), milled, and sieved together to obtain a particle size of $500 \mu \mathrm{m}$. The samples were stored in sealed plastic bags at $-30^{\circ} \mathrm{C}$ until further analysis. A prune (Prunus domestica)-based commercial product (CP) present on the market as tablets was milled and sieved under the same conditions described for blackberry residues. The CP was included in the present study only for comparison of antioxidants, dietary fiber, and color.

2.2. Chemical Composition. The chemical composition of the $\mathrm{BR}$ was determined according to the AOAC [20] for moisture (Official Methods 925.09), ash (Official Methods 923.03), protein (Official Methods 991.20, conversion factor 6.25), ethereal extract (Official Methods 930.39), and AOAC [21] for total, soluble, and insoluble dietary fiber (TDF, SDF, and IDF, resp.). Total carbohydrates were calculated by difference of moisture, ash, protein, ethereal extract, and total dietary fiber values [22].

2.3. Quantitative Analysis of Mineral Composition. A field emission type scanning electron microscope (FE-SEM) (JEOL SSM 6300, Jeol de Mexico, CDMX, Mexico) with a 300,000 magnification range and a resolution of $30 \mathrm{kv}$ was used. The BR sample was placed on a double-sided graphite tape and was then coated with a thin layer of gold $(1 \mathrm{~mm})$ using an ionizing machine (Denton Vacuum LLC, Moorestown, NJ, USA) at a pressure of 20 millitorr and a current of $20 \mathrm{~mA}$ for $4 \mathrm{~min}$. Quantitative analysis of mineral composition was obtained by means of a spectrum that forms part of the scanning electron microscopy.

2.4. Quantification of Organic Acids. Individual organic acids (oxalic, malic, citric, fumaric, and ascorbic) were quantified by high-performance liquid chromatography (HPLC). Briefly, $20 \mathrm{~mL}$ of metaphosphoric acid at $4.5 \%$ (w/v) was added to $500 \mathrm{mg}$ of the sample and the mixture was stirred with magnetic shaking (P-Selecta, Asincro, Spain) for $15 \mathrm{~min}$ under dark conditions. After the mixture was centrifuged (Allegra 25, Beckman Coulter, Palo Alto, CA, USA) at $9000 \mathrm{rpm}$ for $15 \mathrm{~min}$, the supernatant was diluted to a final volume of $25 \mathrm{~mL}$ with metaphosphoric acid 4.5\%. Prior to injection into the HPLC, extracts were filtered through filter paper no. 1242 and then a $0.45 \mu \mathrm{m}$ Millipore PVDF membrane [23]. The HPLC was equipped with an isocratic pump (model PU-II, Micron Analitica, Madrid, Spain), an AS1555 automatic injector (Jasco, Tokyo, Japan), a Sphereclone ODS(2) $250 \times 4.60 \mathrm{~mm}, 5 \mu \mathrm{m}$ Phenomenex column (Torrance, CA, USA), and a UV-visible detector (Thermo Separation Spectra Series UV100, San Jose, CA, USA). The mobile phase was $1.8 \mathrm{mM} \mathrm{H}_{2} \mathrm{SO}_{4}$ at $\mathrm{pH}$ 2.6. UV detection at $215 \mathrm{~nm}$ and a flow rate of $0.4 \mathrm{~mL} / \mathrm{min}$ were used for the analysis of organic acids, while a flow rate of $0.9 \mathrm{~mL} / \mathrm{min}$ and $\mathrm{UV}$ detection at $245 \mathrm{~nm}$ were set for ascorbic acid. Linear calibration curves were obtained for quantification from stock solutions of all the identified compounds (oxalic, malic, citric, fumaric, and ascorbic acids). Data were analyzed using the Biochrom 2000 (version 3.0) software. Identification was made by comparing retention times of commercial pure standards, and quantification was based on the UV signal response, and the resultant peak areas in the chromatograms were plotted against concentrations obtained from standards (1.34, $1.40,1.39,1.45$, and $25-100 \mathrm{mg} / \mathrm{mL}$ for oxalic, malic, citric, fumaric, and ascorbic acids, resp., in metaphosphoric acid $4.5 \%)$. Organic acid contents in blackberry residues were expressed in $\mathrm{mg} / 100 \mathrm{~g}$ of dry basis $(\mathrm{db})$.

2.5. Fatty Acid Profile. Blackberry residues were washed according to previous studies by Zafra-Rojas et al. [24] and Siriwoharn et al. [1] with minor modifications to simulate the industrial process. Briefly, $160 \mathrm{~mL}$ of deionized water was added to $10 \mathrm{~g}$ of sample and centrifuged at $10,000 \mathrm{rpm}$ for 
$10 \mathrm{~min}$; the supernatant was discarded and centrifugation repeated with $80 \mathrm{~mL}$ of deionized water; the resulting precipitate was washed under the same centrifuging conditions with methanol up to six washes until the supernatant was no longer red or was colorless.

Following the procedure suggested by Añorve-Morga et al. [25], $110 \mathrm{~mL}$ of chloroform-methanol $\left(\mathrm{CHCl}_{3}: \mathrm{MeOH}\right.$, $2: 1 \mathrm{vol} / \mathrm{vol})$ was added to the washed samples and vortexed for 5 minutes and stored at $4^{\circ} \mathrm{C}$ for $48 \mathrm{~h}$. Subsequently, $500 \mu \mathrm{L}$ of the aqueous phase containing $\mathrm{CHCl}_{3}: \mathrm{MeOH}$ was transferred to a tube and $1 \mathrm{~mL}$ of boron trifluoride-methanol $\left(\mathrm{BF}_{3}: \mathrm{MeOH}\right)(12.5: 100, \mathrm{vol} / \mathrm{vol})$ was added prior to heating the sample at $95^{\circ} \mathrm{C}$ in a water bath for $6 \mathrm{~min}$ [26]. After the mixture was allowed to cool and $1 \mathrm{~mL}$ of hexane plus $1 \mathrm{~mL}$ of hexane-saturated water was added, it was stirred and the aqueous phase was discarded. Two milliliters of hexane-saturated water was added, stirred, and reserved in a freezer until use. Prior to analysis, the organic phase was evaporated and the fatty acids were taken up in hexane. FAME (methyl esters of fatty acids) were analyzed and identified by comparing their retention times to standards of known amounts (FAME Mix C4-C24 Supelco ${ }^{\circledR}$ by Sigma-Aldrich, St. Louis, MO, USA).

For analysis of the fatty acids, a gas chromatograph (PerkinElmer, Australia) was used: AutoSystem XL equipped with a flame ionization detector (FID) and a Supelco ${ }^{\circledR}$ SP TM-2560 capillary column $(75 \mathrm{~m} \times 0.18 \mathrm{~mm} \times 0.14 \mu \mathrm{m})$ using the splitless injection mode $(1 \mu \mathrm{L})$. The initial column temperature was set at $150^{\circ} \mathrm{C}$, increased at a rate of $4^{\circ} \mathrm{C} / \mathrm{min}$ to $214^{\circ} \mathrm{C}$, held for $2 \mathrm{~min}$, and then increased to $244^{\circ} \mathrm{C}$ at $2.5^{\circ} \mathrm{C} / \mathrm{min}$ and held for $5 \mathrm{~min}$. The injector and detector temperatures were $230^{\circ} \mathrm{C}$ and $250^{\circ} \mathrm{C}$, respectively. The ramp split was approximately $1 \mu \mathrm{L}$ and nitrogen was used as a carrier gas at a constant flow of $1 \mathrm{~mL} / \mathrm{min}$.

2.6. Antioxidants Extraction. Two hundred milligrams of sample (BR and $\mathrm{CP}$ ) was placed in a capped centrifuge tube; $10 \mathrm{~mL}$ of acidic methanol/water $(50: 50, \mathrm{v} / \mathrm{v})$ was added and the tube was thoroughly shaken at room temperature for $1 \mathrm{~h}$. The mixture was centrifuged at $3400 \mathrm{rpm}$ for $20 \mathrm{~min}$ and the supernatant was recovered. Ten milliliters of acetone/water $(70: 30, \mathrm{v} / \mathrm{v})$ was added to the residue and the shaking and centrifugation were repeated. Methanolic and acetone extracts were combined and used to determine the antioxidant capacity associated with extractable antioxidants [27].

2.6.1. Determination of Total Phenolic Content (TPC). Total phenolic content was determined by the Folin-Ciocalteu procedure [28]. Briefly, $100 \mu \mathrm{L}$ of the sample was mixed with $500 \mu \mathrm{L}$ of $1: 10$ diluted Folin-Ciocalteu reagent. Then, $400 \mu \mathrm{L}$ (7.5\%) of sodium carbonate was added and the mixture was incubated for $30 \mathrm{~min}$ at room temperature. The absorbance of the mixture was measured at $765 \mathrm{~nm}$ in the microplate reader (Power Wave XS UV-Biotek, software Gen5 2.09, Winooski, VT, USA). The standard curve was developed with concentrations of $0,100,200$, and $300 \mathrm{mg}$ of gallic acid/L. Gallic acid was used as reference standard and the results were expressed as $\mathrm{mg}$ of gallic acid equivalents per 100 grams of dry basis (mg GAE/100 g db) of blackberry residues and commercial product.

2.6.2. Determination of Anthocyanins. The anthocyanin content was determined through the differential $\mathrm{pH}$ method [29]. Two buffer solutions were prepared: $0.025 \mathrm{M}$ potassium chloride at $\mathrm{pH} 1.0$ and $0.4 \mathrm{M}$ sodium acetate at $\mathrm{pH}$ 4.5. The $\mathrm{pH}$ was adjusted by adding concentrated $\mathrm{HCl}$. The extracts of blackberry residues and prune (commercial product) were diluted in these two buffer solutions. After 15 min under dark conditions at room temperature, absorbance was measured at 510 and $700 \mathrm{~nm}$ using a microplate reader (Power Wave XS UV-Biotek, software Gen5 2.09, Winooski, VT, USA). The absorbance of the anthocyanins was calculated according to

$$
\begin{aligned}
\text { Abs }= & \left(\mathrm{Abs}_{510}-\mathrm{Abs}_{700}\right) \mathrm{pH}_{1.0} \\
& -\left(\mathrm{Abs}_{510}-\mathrm{Abs}_{700}\right) \mathrm{pH}_{4.5} .
\end{aligned}
$$

The concentration of anthocyanins in the extracts was calculated according to

$$
\text { Anthocyanins }(\mathrm{mg} / \mathrm{L})=\frac{(\mathrm{Abs} \times \mathrm{MW} \times \mathrm{DF} \times 1000)}{\varepsilon \times 0.52},
$$

where Abs is the absorbance, MW is the molecular weight, DF is the dilution factor, and $\varepsilon$ is the molar absorptivity, considering the molar absorptivity $(\varepsilon)$ of $26,900 \mathrm{~L} \mathrm{~mol}^{-1} \mathrm{~cm}^{-1}$, the molecular weight of $449.2 \mathrm{~g} / \mathrm{mol}$ for cyanidin-3-glucoside, and the path length $(0.52 \mathrm{~cm})$ of the well. The results were expressed as $\mathrm{mg}$ of cyanidin-3-glucoside equivalent/100 grams on a dry basis ( $\mathrm{mg}$ cy-3-gl/100 g db).

\subsection{Antioxidant Capacity}

2.7.1. ABTS Method. The radical cation $\left(\mathrm{ABTS}^{\circ+}\right)$ was produced by reacting $7 \mathrm{mM}$ ABTS stock solution with $2.45 \mathrm{mM}$ potassium persulfate under dark conditions at room temperature for $16 \mathrm{~h}$ before use. The ABTS solution was diluted with deionized water until an absorbance of $0.70 \pm 0.10$ at $754 \mathrm{~nm}$. An aliquot of $20 \mu \mathrm{L}$ of the extract was added to $980 \mu \mathrm{L}$ of diluted ABTS solution, and absorbance readings were taken after incubation for $7 \mathrm{~min}$ at room temperature. The absorbance of the mixture was measured at $754 \mathrm{~nm}$ in a microplate reader (Power Wave XS UV-Biotek, software Gen5 2.09, Winooski, VT, USA). The standard curve was linear with concentrations of $0,10,20,30,40$, and $50 \mathrm{mg}$ of ascorbic acid/L [30]. The antioxidant capacity of blackberry residues and commercial product (prune) was expressed as milligrams of ascorbic acid equivalents per 100 grams of dry basis (mg $\mathrm{AAE} / 100 \mathrm{~g} \mathrm{db})$.

2.7.2. DPPH Method. Antiradical activity was measured with 1,1-diphenyl-2-picrylhydrazyl radical (DPPH) [31]. An ethanolic solution $(7.4 \mathrm{mg} / 100 \mathrm{~mL})$ of the stable DPPH radical was prepared. Then, $100 \mu \mathrm{L}$ of the extract was taken into vials and $500 \mu \mathrm{L}$ of the DPPH solution was added, and the mixture was left to stand for $1 \mathrm{~h}$ at room temperature. Finally, absorbance was measured at $520 \mathrm{~nm}$ using a microplate reader (Power Wave XS UV-Biotek, software Gen5 2.09, 
Winooski, VT, USA). The standard curve was developed with concentrations of $0,50,100,200$, and $300 \mu \mathrm{mol}$ of Trolox. Free-radical scavenging activity was expressed as $\mu \mathrm{mol}$ of Trolox equivalents per $100 \mathrm{~g}$ of dry basis $(\mu \mathrm{mol} \mathrm{TE} / 100 \mathrm{~g} \mathrm{db})$ of blackberry residues and commercial product.

2.7.3. Ferric Reducing Antioxidant Power (FRAP). The FRAP was assayed according to Benzie and Strain [32] with some modifications. The stock solutions included $300 \mathrm{mM}$ acetate

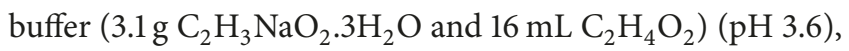
$10 \mathrm{mM}$ TPTZ (2,4,6-tripyridyl-s-triazine) solution in $40 \mathrm{mM}$ $\mathrm{HCl}$, and $20 \mathrm{mM} \mathrm{FeCl} \cdot 6 \mathrm{H}_{2} \mathrm{O}$ solution. The fresh solution prepared by mixing $25 \mathrm{~mL}$ acetate buffer, $2.5 \mathrm{~mL}$ TPTZ solution, and $2.5 \mathrm{~mL} \mathrm{FeCl} \cdot 6 \mathrm{H}_{2} \mathrm{O}$ solution was warmed at $37^{\circ} \mathrm{C}$ before use. The sample $(30 \mu \mathrm{L})$ was mixed with $90 \mu \mathrm{L}$ of distilled water and $900 \mu \mathrm{L}$ of the FRAP solution for $10 \mathrm{~min}$ in the dark. Absorbance was measured at $593 \mathrm{~nm}$ using a microplate reader (Power Wave XS UV-Biotek, software Gen5 2.09, Winooski, VT, USA). The standard curve was developed with concentrations of $0,200,400,600,800$, and $1000 \mu \mathrm{mol}$ ferrous sulfate $\left(\mathrm{FeSO}_{4}\right) 5 \mathrm{M}$, and the results were expressed as $\mu \mathrm{mol} \mathrm{Fe}(\mathrm{II})$ per $100 \mathrm{~g}$ dry basis $(\mu \mathrm{mol} \mathrm{Fe}(\mathrm{II}) / 100 \mathrm{~g} \mathrm{db})$ of blackberry residues and commercial product.

\subsection{Properties of Dietary Fiber}

2.8.1. Water Retention Capacity (WRC). An aliquot ( $0.5 \mathrm{~g}$ ) of $\mathrm{BR}$ and $\mathrm{CP}$ was placed in $15 \mathrm{~mL}$ centrifuge tubes and $10 \mathrm{~mL}$ of distilled water was added. The tubes were shaken manually for 10 minutes and then allowed to stand for $24 \mathrm{~h}$ at room temperature prior to centrifugation (Hamilton Bell VanGuard V6500, New Jersey, USA) at $3400 \mathrm{rpm}$ for 20 minutes. Immediately, the supernatant was removed and the pellet weighed. The water retention capacity was measured as the amount of water retained by the sample ( $\mathrm{g} / \mathrm{g}$ dry basis) $[33,34]$ and was calculated by

$$
\mathrm{WRC}(\mathrm{g} / \mathrm{g})=\frac{(\mathrm{WFS}-\mathrm{WDS})}{\mathrm{WDS}},
$$

where WFS is the weight of the fresh sample (g) and WDS is the weight of the dry sample $(\mathrm{g})$.

2.8.2. Swelling Capacity (SC). The lyophilized samples $(200 \mathrm{mg})$ were placed in a graduated cylinder $(0.1 \mathrm{~mL})$ and the volume occupied $\left(V_{0}\right)(\mathrm{mL})$ was measured. Then, $10 \mathrm{~mL}$ of distilled water was added and the mixture was stirred manually for $5 \mathrm{~min}$ and allowed to stand for 24 hours at room temperature. The final volume of the samples $\left(V_{1}\right)(\mathrm{mL})$ was measured $[33,35]$ and the swelling capacity of BR and CP $(\mathrm{mL} / \mathrm{g})$ was calculated using

$$
\mathrm{SC}(\mathrm{mL} / \mathrm{g})=\frac{\left(V_{1}-V_{0}\right)}{\mathrm{sw}},
$$

where $V_{1}$ is the final volume $(\mathrm{mL}), V_{0}$ is the volume occupied by the lyophilized sample $(\mathrm{mL})$, and sw is the sample weight (g).
2.8.3. Fat Absorption Capacity (FAC). Five hundred milligrams (WDS) of BR and CP was placed in separated $15 \mathrm{~mL}$ centrifuge tubes and $10 \mathrm{~mL}$ of sunflower seed oil was added. The mixtures were shaken manually for 10 minutes and then allowed to stand for $24 \mathrm{~h}$ at room temperature. Samples were centrifuged at $3400 \mathrm{rpm}$ (Hamilton Bell VanGuard V6500, New Jersey, USA) for 20 minutes and immediately the supernatant was removed and the pellet weighed (WFS). The fat absorption capacity was measured as the amount of fat retained by the sample ( $\mathrm{mL} / \mathrm{g}$ dry basis) $[33,34]$ and was calculated using

$$
\operatorname{FAC}(\mathrm{mL} / \mathrm{g})=\frac{(\mathrm{WFS}-\mathrm{WDS})}{\mathrm{WDS}},
$$

where WFS is the weight of the fresh sample (g) and WDS is the weight of the dry sample $(\mathrm{g})$.

2.9. Color Measurement. Color of BR and CP was measured using a colorimeter (Konica Minolta CM-608d, Sensing, Inc., Japan) set with the D65 illuminant and $10^{\circ}$ observer angle. The CIE-Lab values were recorded, where $L^{*}$ indicates lightness ( $L=0$ or 100 indicates black or white, resp.); $a^{*}$ is the axis of chromaticity between green $(-)$ and red $(+)$, and $b^{*}$ is the axis between blue (-) and yellow $(+)$. Numerical values of $L^{*}$, $a^{*}$, and $b^{*}$ were used to obtain chroma $\left(C=\left[a^{2}+b^{2}\right]^{1 / 2}\right)$ and Hue angle $\left(h^{\circ}\right)\left(h^{\circ}=\operatorname{tg}^{-1}(b / a)\right)[36]$.

2.10. Statistical Analysis. All experiments were carried out in triplicate and expressed as mean \pm standard deviation (SD). The variables used to compare the blackberry residues with commercial product were analyzed by a $t$-test and a confidence level of $95 \%$ using the SPSS ${ }^{\circledR}$ System for WIN $^{\mathrm{TM}}$ version 15.0 .

\section{Results and Discussion}

3.1. Chemical Composition, Minerals, and Organic Acids. Table 1 shows the chemical composition, mineral content, and organic acids of blackberry residues. The BR had a moisture content of $74.83 \pm 0.76 \%$ and could be described as a semisolid fibrous product from which the liquid has been extracted during juice production. Other fruit residues have similar moisture percentages, such as blackberry (Rubus sp.), mango (Mangifera indica), and guava (Psidium guajava) residues (values between 70 and 90\%) $[11,37]$.

Protein $(2.60 \pm 0.11 \%)$ and lipid $(1.84 \pm 0.03 \%)$ content in BR was higher than values reported for orange, guava, soursop, and mango residues, which ranged from 0.6 to $1.9 \%$ and from 0.25 to $0.48 \%$, respectively [37]. Differences could be attributed to the high seed content in BR and the fact that these are mainly composed of oils [38]. Carbohydrates $(9.07 \pm 0.80 \%)$ and total dietary fiber $(11.12 \pm 0.22 \%)$ were the major components after moisture, while ashes were minor constituents $(0.54 \pm 0.02 \%)$, although they were higher than ash percentages reported for blackberries bagasse by Pasquel Reátegui et al. [11].

The minerals found in BR were sodium, magnesium, potassium, calcium, iron, sulfur, silicon, and chlorine (Table 1). 
TABLE 1: Chemical composition, analysis of minerals content, and organic acids of blackberry residues.

\begin{tabular}{|c|c|}
\hline & Blackberry residues $^{\mathrm{a}}$ \\
\hline \multicolumn{2}{|l|}{ Composition (\%) } \\
\hline Moisture & $74.83 \pm 0.76$ \\
\hline Protein & $2.60 \pm 0.11$ \\
\hline Lipids & $1.84 \pm 0.03$ \\
\hline Total carbohydrates & $9.07 \pm 0.80$ \\
\hline Total dietary fiber & $11.12 \pm 0.22$ \\
\hline Ash & $0.54 \pm 0.02$ \\
\hline \multicolumn{2}{|l|}{ Element (\%) } \\
\hline $\mathrm{C}$ & $48.02 \pm 4.69$ \\
\hline $\mathrm{N}$ & $7.54 \pm 0.43$ \\
\hline $\mathrm{O}$ & $43.04 \pm 4.16$ \\
\hline $\mathrm{P}$ & $0.19 \pm 0.08$ \\
\hline $\mathrm{Na}$ & $0.01 \pm 0.01$ \\
\hline $\mathrm{Mg}$ & $0.11 \pm 0.05$ \\
\hline $\mathrm{K}$ & $0.81 \pm 0.17$ \\
\hline $\mathrm{Ca}$ & $0.08 \pm 0.04$ \\
\hline $\mathrm{Fe}$ & $0.03 \pm 0.05$ \\
\hline $\mathrm{Cu}$ & - \\
\hline $\mathrm{Zn}$ & - \\
\hline $\mathrm{Mn}$ & - \\
\hline$S$ & $0.05 \pm 0.01$ \\
\hline $\mathrm{Si}$ & $0.02 \pm 0.04$ \\
\hline $\mathrm{Cl}$ & $0.06 \pm 0.05$ \\
\hline \multicolumn{2}{|c|}{ Organic acids (mg/100 g db) } \\
\hline Oxalic acid & $59.51 \pm 8.18$ \\
\hline Malic acid & $5706.37 \pm 123.38$ \\
\hline Citric acid & $125.54 \pm 0.61$ \\
\hline Fumaric acid & $230.25 \pm 2.47$ \\
\hline Ascorbic acid & $6.00 \pm 1.00$ \\
\hline
\end{tabular}

${ }^{\mathrm{a}}$ Mean \pm standard deviation $(n=3)$.

In other blackberry studies, in addition to the mentioned minerals, copper, zinc, manganese, and selenium were also found [39-41]. These differences may be mainly attributed to the type of soil in which these fruits were cultivated; for instance, the soil of Atotonilco, Hidalgo, Mexico (where the blackberry was harvested) consists of layers of volcanic ash and pumice and a conglomerate of gravel and sand characterized by the presence of potassium and other minerals in low concentrations [42].

Many fruits accumulate organic acids in their pulp and peel at certain stages of their development [43, 44]. In the $\mathrm{BR}$, ascorbic acid content was low $(6.00 \pm 1.00 \mathrm{mg} / 100 \mathrm{~g} \mathrm{db})$ while malic acid was in higher concentrations (5706.37 \pm $123.38 \mathrm{mg} / 100 \mathrm{~g} \mathrm{db}$ ) (Table 1) as has been reported for several fruits such as strawberry tree (Arbutus unedo L., Ericaceae), blackberry (Rubus ulmifolius Schott), and red apples (Malus domestica Borkh.) [45-47]. Evidence suggests that organic acids such as malic or citric acids may have a positive health benefit as antioxidants thanks to their ability to chelate metals [48]. On the other hand, environmental factors and
TABLE 2: Fatty acids profile of blackberry residues (mg/100 g).

\begin{tabular}{ll}
\hline Palmitic acid (C16:0) & $1.68 \pm 0.40$ \\
Linolenic acid (C18:3n-3) & $0.43 \pm 0.07$ \\
Arachidic acid (C20:0) & $7.68 \pm 1.88$ \\
Eicosenoic acid (C20:1) & $0.20 \pm 0.00$ \\
\hline Mean \pm standard deviation $(n=2)$. &
\end{tabular}

cultivation practices (e.g., temperature, cultivar, minerals, and water availability) could affect the content of these organic acids in fruits [43].

3.2. Fatty Acids Profile. Table 2 shows the fatty acids profile of BR. Four fatty acids were found and corresponded to $9.99 \mathrm{mg} / 100 \mathrm{~g}$ of blackberry residues. The saturated palmitic (C16:0) and arachidic (C20:0) acids were found in higher quantities as compared to the polyunsaturated and monounsaturated linolenic (C18:3n-3) and eicosenoic (C20:1) acids. These same fatty acids have been found in oil seeds in different species of blackberries (Rubus ursinus var. Marion and Rubus laciniatus Willd. var. Evergreen, Rubus ulmifolius var. Schott, and Rubus fruticosus) $[38,49,50]$. However, the amount found in the BR was lower than the values reported in these studies probably due to the presence of peel and pulp in addition to seeds so that the final concentration was affected.

3.3. Total Phenolic Content and Anthocyanins. The whole blackberry fruit is a good source of antioxidant compounds and has considerable levels of phenolic compounds, including anthocyanins. In blackberry (Rubus fruticosus L. var. Caingangue) residues such as peel and seeds, high concentrations (366 to $736 \mathrm{mg}$ GAE/100 $\mathrm{g}$ fresh residues) have also been reported [15]. The BR exhibited significantly higher total phenolic content $(p<0.05)$ and anthocyanins in comparison with the commercial product in which anthocyanins were absent (Table 3), probably due to complete degradation during the transformation of fresh plums of prunes [51]. The phenolic content of the BR was higher than that reported by Huang et al. [52] for whole rabbiteye blueberry fruits (Vaccinium ashei cv. Brightwell) including peel, seeds, and pulp, for thornless blackberry (Rubus laciniatus cv. Hull), and for strawberry (Fragaria $\times$ ananassa cv. Toyonoka). The values for anthocyanins in the present study were similar to those described by Dai et al. [53] for Hull blackberry puree (534 mg/100 g db).

Patras et al. [54] evaluated TPC in strawberry (Fragaria $\times$ ananassa cv. EI Santa) and blackberry (Rubus fruticosus cv. Loch Ness) puree, and the amount of phenols (855 and $1694 \mathrm{mg} \mathrm{GAE} / 100 \mathrm{~g} \mathrm{db}$, resp.) was lower than the value obtained for our BR. Differences in the total concentration of phenols in vegetables could be attributed to variations in the composition of the food matrix, geographical origin, cultivar/genotype, maturity, time and type of drying, and storage time [55]. Other factors that affect the recovery of phenolic compounds are extraction methods and conditions such as extraction temperature, time, particle size, and type of solvent $[11,56,57]$. 
TABLE 3: Total phenolic content, anthocyanins, and antioxidant capacity of blackberry residues ${ }^{\mathrm{a}}$ and commercial product.

\begin{tabular}{lcr}
\hline & BR $^{\mathrm{a}}$ & Commercial product \\
\hline Parameters & & \\
TPC $(\mathrm{mg} \mathrm{GAE} / 100 \mathrm{~g} \mathrm{db})$ & $4016.43 \pm 13.44^{*}$ & $1362.98 \pm 52.84$ \\
Anthocyanins $(\mathrm{mg} / 100 \mathrm{~g} \mathrm{db})$ & $364.53 \pm 7.36^{*}$ & $0.00 \pm 0.00$ \\
Antioxidant capacity & & $267.06 \pm 13.86$ \\
ABTS $(\mathrm{mg} \mathrm{AAE} / 100 \mathrm{~g} \mathrm{db})$ & $5422.38 \pm 71.50^{*}$ & $16655.88 \pm 272.02$ \\
DPPH $(\mu \mathrm{mol} \mathrm{TE} / 100 \mathrm{~g} \mathrm{db})$ & $13656.27 \pm 532.66^{*}$ & $2842.23 \pm 109.41$ \\
FRAP $(\mu \mathrm{mol} \mathrm{Fe}(\mathrm{II}) / 100 \mathrm{~g} \mathrm{db})$ & $12511.44 \pm 147.39^{*}$ &
\end{tabular}

Mean \pm standard deviation $(n=3)$. * indicates significant difference $(p<0.05)$ between samples.

TABLE 4: Dietary fiber properties of blackberry residues and commercial product.

\begin{tabular}{lcc}
\hline & BR $^{\mathrm{a}}$ & Commercial product $^{\mathrm{b}}$ \\
\hline Parameters & & $8.06 \pm 0.12$ \\
$\quad$ Total dietary fiber (\%) & $44.26 \pm 0.09^{*}$ & $1.96 \pm 0.08$ \\
$\quad$ Soluble dietary fiber (\%) & $5.90 \pm 0.52^{*}$ & $6.09 \pm 0.29$ \\
$\quad$ Insoluble dietary fiber (\%) & $38.35 \pm 0.39^{*}$ & $0.00 \pm 0.00$ \\
Properties & & $0.00 \pm 0.00$ \\
$\quad$ Water retention capacity (g/g) & $2.94 \pm 0.10^{*}$ & $1.49 \pm 0.02$ \\
Swelling capacity (mL/g) & $5.00 \pm 0.00^{*}$ & $1.98 \pm 0.03^{*}$ \\
Fat absorption capacity (mL/g)
\end{tabular}

${ }^{\mathrm{a}} \mathrm{BR}$ : blackberry residues. ${ }^{\mathrm{b}}$ Prune. $*$ indicates significant difference $(p<0.05)$ between samples.

3.4. Antioxidant Capacity. BR presented high antioxidant capacity by ABTS and FRAP, but low by DPPH $(p<0.05)$ compared with the CP (Table 3 ). The antioxidant capacity by ABTS and the iron reduction ability of the BR were 20 and 4 times, respectively, those of the $\mathrm{CP}$ which in contrast had a DPPH value 1.2 times that of the BR. The reported antioxidant capacity of fruit residues such as pulp, peel, and seeds from strawberry (Fragaria vesca L.), carrot (Daucus carota L. spp. sativus var. atrorubens Alef.), and blueberry (202 mg VCEAC/100 g, $10190 \mu \mathrm{mol} \mathrm{TE} / 100 \mathrm{~g} \mathrm{db}$, and $10400 \mu \mathrm{mol} \mathrm{Fe}(\mathrm{II}) / 100 \mathrm{~g} \mathrm{db}$, for ABTS, DPPH, and FRAP, resp.) $[30,58,59]$ was lower than the values found for $\mathrm{BR}$ in the present study. The responsible compounds for the antioxidant activity are mainly phenols [60], but some pigments such as anthocyanins also contribute to the amount of phenolic compounds. The basic structural orientation of these compounds determines their antioxidant activity since the hydroxyl group has a higher ability to donate hydrogen atoms to free radicals [61]. Moreover, the position of the hydroxyl groups appears to be more important than their number to act as antioxidants [62]. Phenolic compounds also contribute by transferring an electron to reduce the ferric ion (III) to its ferrous (II) form [60]. But the presence of lipids as tocopherols that are found in seeds [38] may impact the overall antioxidant activity of the evaluated BR that does contain seeds.

3.5. Dietary Fiber and Functional Properties. It is well known that agroindustrial waste is rich in dietary fiber. Dietary fiber contains significant amounts of antioxidant compounds and other substances with positive effects on health [63].
Total, soluble, and insoluble dietary fiber and functional properties of BR and CP are described in Table 4. In general, the percentage of total dietary fiber and their properties was higher in BR compared with CP. The analyzed functional properties such as WRC, SC, and FAC were significantly higher $(p<0.05)$ in BR $(2.94 \pm 0.10 \mathrm{~g} / \mathrm{g}, 5.00 \pm 0.00 \mathrm{~mL} / \mathrm{g}$, and $1.98 \pm 0.03 \mathrm{~mL} / \mathrm{g}$, resp.). The total fiber content of the BR was similar to the one described for grapefruit fiber $(44 \mathrm{~g} / 100 \mathrm{~g})$ but SC was higher than that reported for oat and apples fibers (2.3 and $3.4 \mathrm{~mL} / \mathrm{g}$, resp.) $[64,65]$. In terms of WRC $(9.7 \mathrm{~g} / \mathrm{g})$, our values were lower than those reported by Basanta et al. [66] who evaluated cherry fibers. The content of soluble dietary fiber affects SC, and insoluble dietary fiber determines the WRC and FAC [67]; hence, the properties of dietary fiber depend on the proportion of SDF and IDF. Since the BR contains IDF, it may help to ease constipation, increase excretion, and bind bile salts, cholesterol, and carcinogenic compounds allowing their excretion through the feces [68, 69]. Intake of IDF may also prevent conditions such as colon cancer, hypercholesterolemia, and intoxication. The BR also exhibited a high capacity to increase its volume in excess of water, which may contribute to enhancing satiety thanks to its content of SDF $[64,70]$.

3.6. Color Parameters. Color is an important quality attribute because it can condition consumer acceptability. Table 5 shows the color parameters for BR and CP. The luminosity $\left(L^{*}\right)$ for both samples was significantly different $(p<0.05)$; BR presented low values, and according to the $a^{*}$ and $b^{*}$ axes, the BR and CP were found in the reddish quadrant. The Hue angle can be between $0^{\circ}$ and $90^{\circ}$, representing the red $\left(0^{\circ}\right)$ 
TABLE 5: Color parameters of blackberry residues and commercial product.

\begin{tabular}{lcc}
\hline Color parameters & BR $^{\mathrm{a}}$ & Commercial product $^{\mathrm{b}}$ \\
\hline$L^{*}$ & $16.73 \pm 0.00^{*}$ & $37.97 \pm 0.68$ \\
$a^{*}$ & $16.77 \pm 0.03^{*}$ & $2.49 \pm 0.08$ \\
$b^{*}$ & $10.88 \pm 0.00$ & $11.38 \pm 0.35$ \\
$h^{\circ}$ & $32.98 \pm 0.06^{*}$ & $77.64 \pm 0.63$ \\
Chroma & $20.00 \pm 0.02^{*}$ & $11.65 \pm 0.33$ \\
\hline
\end{tabular}

${ }^{a}$ BR: blackberry residues. ${ }^{b}$ Prune. $*$ indicates significant difference $(p<0.05)$ between samples.

and orange-yellow $\left(90^{\circ}\right)$ colors; based on this value, the BR is within the red-orange tone, and the $\mathrm{CP}$ exhibited a yellow tone.

Color saturation (chroma) was between 0 and 60 and results showed that the $\mathrm{CP}$ had lower saturation than the $\mathrm{BR}$ [71, 72]. Malien-Aubert et al. [73] evaluated the color of some commercial extracts from grapes (Vitis vinifera), elderberry (Sambucus nigra), purple carrot (Daucus carota), red radish (Raphanus sativus), black currant (Ribes nigrum), red cabbage (Brassica oleracea), and chokeberry (Aronia melanocarpa); the chroma values from these two last sources were close to the values obtained for the BR (around 20). Red, blue, and purple colors in fruits depend on the anthocyanins and also the number and orientation of the hydroxyl and methoxyl groups of the molecule; for example, an increase in hydroxylation produces a shift to blue tones whereas an increase in methoxylation generates red coloration [74]. This suggests that the BR may contain a high amount of methoxyl groups. According to the European Union, all dyes derived from anthocyanins are recognized as natural dyes under the E163 classification, ranging from E163a (cyanidin: red food coloring) to E165f (petunidin: dark red food coloring) [72]. Therefore, based on our results, the BR could be a good source of natural dyes thanks to the presence of anthocyanins.

\section{Conclusions}

The results demonstrated that blackberry residues are a good source of organic acids and contain elevated amounts of phenolic compounds and anthocyanins and antioxidant capacity compared to the prune-based commercial product. These residues also exhibited better dietary fiber functional properties and a rich reddish color which make them a potential source of components with a beneficial role in human health, particularly for patients with chronic noncommunicable diseases.

\section{Conflicts of Interest}

The authors declare that there are no conflicts of interest.

\section{Acknowledgments}

The first author would like to thank the Consejo Nacional de Ciencia y Tecnología (CONACyT) for the fellowship assigned (no. 555688). The authors also thank Mr. Isidoro, producer of Atotonilco, Hidalgo, Mexico, for the contribution of the blackberry.

\section{References}

[1] T. Siriwoharn, R. E. Wrolstad, and R. W. Durst, "Identification of ellagic acid in blackberry juice sediment," Journal of Food Science, vol. 70, no. 3, pp. C189-C197, 2005.

[2] L. E. Laroze, B. Díaz-Reinoso, A. Moure, M. E. Zúñiga, and H. Domínguez, "Extraction of antioxidants from several berries pressing wastes using conventional and supercritical solvents," European Food Research and Technology, vol. 231, no. 5, pp. 669677, 2010.

[3] F. V. Dulf, S. Andrei, A. Bunea, and C. Socaciu, "Fatty acid and phytosterol contents of some Romanian wild and cultivated berry pomaces," Chemical Papers, vol. 66, no. 10, pp. 925-934, 2012.

[4] I. Badjakov, M. Nikolova, R. Gevrenova, V. Kondakova, E. Todorovska, and A. Atanassov, "Bioactive compounds in small fruits and their influence on human health," Biotechnology \& Biotechnological Equipment, vol. 22, no. 1, pp. 581-587, 2008.

[5] J. G. Bordonaba and L. A. Terry, "Manipulating the taste-related composition of strawberry fruits (Fragaria $\mathrm{x}$ ananassa) from different cultivars using deficit irrigation," Food Chemistry, vol. 122, no. 4, pp. 1020-1026, 2010.

[6] M. Mikulic-Petkovsek, V. Schmitzer, A. Slatnar, F. Stampar, and R. Veberic, "Composition of sugars, organic acids, and total phenolics in 25 wild or cultivated berry species," Journal of Food Science, vol. 77, no. 10, pp. C1064-C1070, 2012.

[7] A. Moure, J. M. Cruz, D. Franco et al., "Natural antioxidants from residual sources," Food Chemistry, vol. 72, no. 2, pp. 145$171,2001$.

[8] J. Who and F. E. Consultation, "Diet, nutrition and the prevention of chronic diseases," Tech. Rep., 2003.

[9] T. Siriwoharn and R. E. Wrolstad, "Polyphenolic composition of marion and evergreen blackberries," Journal of Food Science, vol. 69, no. 4, pp. FCT233-FCT240, 2004.

[10] J. K. Rutz, G. B. Voss, and R. C. Zambiazi, "Influence of the degree of maturation on the bioactivecompounds in backberry (Rubus spp.) cv. Tupy," Journal of Food and Nutrition Sciences, vol. 03, no. 10, pp. 1453-1460, 2012.

[11] J. L. Pasquel Reátegui, A. P. D. F. Machado, G. F. Barbero, C. A. Rezende, and J. Martínez, "Extraction of antioxidant compounds from blackberry (Rubus sp.) bagasse using supercritical CO2 assisted by ultrasound," The Journal of Supercritical Fluids, vol. 94, pp. 223-233, 2014.

[12] E. F. de Vargas, A. Jablonski, S. H. Flôres, and A. D. O. Rios, "Obtention of Natural Dyes from Industrial Blackberry Pulp Residues (Rubus sp)," Journal of Food Processing and Preservation, vol. 41, no. 1, Article ID e12777, 2017.

[13] A. P. Da Fonseca, A. L. Duarte, G. Fernández, and J. Martínez, "Recovery of anthocyanins from residues of Rubus fruticosus, Vaccinium myrtillus and Eugenia brasiliensis by ultrasound 
assisted extraction, pressurized liquid extraction and their combination," Food Chemistry, vol. 231, no. 1, p. 10, 2017.

[14] A. Wajs-Bonikowska, A. Stobiecka, R. Bonikowski, A. Krajewska, M. Sikora, and J. Kula, "A comparative study on composition and antioxidant activities of supercritical carbon dioxide, hexane and ethanol extracts from blackberry (Rubus fruticosus) growing in Poland," Journal of the Science of Food and Agriculture, vol. 97, no. 11, pp. 3576-3583, 2017.

[15] A. P. Da Fonseca, J. L. Pasquel-Reátegui, G. Fernández, and J. Martínez, "Pressurized liquid extraction of bioactive compounds from blackberry (Rubus fruticosus L.) residues: a comparison with conventional methods," in Proceedings of the, vol. 77, pp. 675-683, 2015.

[16] F. Saura-Calixto, "Dietary fiber as a carrier of dietary antioxidants: An essential physiological function," Journal of Agricultural and Food Chemistry, vol. 59, no. 1, pp. 43-49, 2011.

[17] L. Hooper and A. Cassidy, "A review of the health care potential of bioactive compounds," Journal of the Science of Food and Agriculture, vol. 86, no. 12, pp. 1805-1813, 2006.

[18] S. K. Jaganathan, M. V. Vellayappan, G. Narasimhan et al., "Chemopreventive effect of apple and berry fruits against colon cancer," World Journal of Gastroenterology, vol. 20, no. 45, pp. 17029-17036, 2014.

[19] J. W. Anderson, P. Baird, R. H. Davis et al., "Health benefits of dietary fiber," Nutrition reviews, vol. 67, no. 4, pp. 188-205, 2009.

[20] AOAC, Official Methods of Analysis, AOAC International, Gaithersburg. Md, USA, 18th edition, 2005.

[21] AOAC, Official Methods of Analysis, AOAC International, Gaithersburg. Md, USA, 16th edition, 1999.

[22] P. Morales, E. Ramírez-Moreno, M. D. C. Sanchez-Mata, A. M. Carvalho, and I. C. F. R. Ferreira, "Nutritional and antioxidant properties of pulp and seeds of two xoconostle cultivars (Opuntia joconostle F.A.C. Weber ex Diguet and Opuntia matudae Scheinvar) of high consumption in Mexico," Food Research International, vol. 46, no. 1, pp. 279-285, 2012.

[23] J. Prohens, M. C. Sánchez, A. Rodríguez-Burruezo, M. Cámara, E. Torija, and F. Nuez, "Morphological and physico-chemical characteristics of fruits of pepino (Solanum muricatum), wild relatives (S. caripense and S. tabanoense) and interspecific hybrids. Implications in pepino breeding," European Journal of Horticultural Science, vol. 70, no. 5, pp. 224-230, 2005.

[24] Q. Y. Zafra-Rojas, N. S. Cruz-Cansino, A. Quintero-Lira et al., "Application of ultrasound in a closed system: optimum condition for antioxidants extraction of blackberry (Rubus fructicosus) residues," Molecules, vol. 21, no. 7, pp. 950-963, 2016.

[25] J. Añorve-Morga, A. Castañeda-Ovando, A. Cepeda-Saez et al., "Microextraction method of medium and long chain fatty acids from milk," Food Chemistry, vol. 172, pp. 456-461, 2015.

[26] L. D. Metcalfe and A. A. Schmitz, "The rapid preparation of fatty acid esters for gas chromatographic analysis," Analytical Chemistry, vol. 33, no. 3, pp. 363-364, 1961.

[27] F. Saura-Calixto, J. Serrano, and I. Goñi, "Intake and bioaccessibility of total polyphenols in a whole diet," Food Chemistry, vol. 101, no. 2, pp. 492-501, 2007.

[28] V. Singleton and J. A. Rossi, "Colorimetry of total phenolics with phosphomolybdic-phosphotungstic acid reagents," American Journal of Enology and Viticulture, vol. 16, pp. 144-158, 1965.

[29] M. M. Giusti and R. E. Wrolstad, "Anthocyanins, characterization, and measurement of anthocyanins by UVvisible spectroscopy," in in Current protocols in Food Analytical Chemistry, R. E. Wrolstad and and S. J. Schwartz, Eds., pp. F1-F2, Editorial John Wiley Sons, Inc, New York, NY, USA, 2001.
[30] E. M. Kuskoski, A. G. Asuero, A. M. Troncoso, J. Mancini-Filho, and R. Fett, "Aplicación de diversos métodos químicos para determinar actividad antioxidante en pulpa de frutos," Ciência e Tecnologia de Alimentos, vol. 25, no. 4, pp. 726-732, 2005.

[31] F. J. Morales and S. Jiménez-Pérez, "Free radical scavenging capacity of Maillard reaction products as related to colour and fluorescence," Food Chemistry, vol. 72, no. 1, pp. 119-125, 2001.

[32] I. F. F. Benzie and J. J. Strain, "The ferric reducing ability of plasma (FRAP) as a measure of 'antioxidant power': the FRAP assay," Analytical Biochemistry, vol. 239, no. 1, pp. 70-76, 1996.

[33] S. A. Lajolo and D. N. Wensel, “Temas en tecnologea de alimentos," in Fibra dietetica, vol. 2, pp. 29-42, Instituto Politecnico Nacional, Mexico, D.F, 1998.

[34] J. A. Robertson, F. D. De Monredon, P. Dysseler, F. Guillon, R. Amadò, and J.-F. Thibault, "Hydration properties of dietary fibre and resistant starch: A European collaborative study," LWT-Food Science and Technology, vol. 33, no. 2, pp. 72-79, 2000.

[35] S. N. Raghavendra, S. R. Ramachandra Swamy, N. K. Rastogi, K. S. M. S. Raghavarao, S. Kumar, and R. N. Tharanathan, "Grinding characteristics and hydration properties of coconut residue: a source of dietary fiber," Journal of Food Engineering, vol. 72, no. 3, pp. 281-286, 2006.

[36] F. J. Francis, "Color quality evaluation of horticultural crops," HortScience, vol. 15, pp. 58-59, 1980.

[37] S. Milena, L. Montoya, and F. Orozco, "Valorización de residuos agroindustriales frutas en Medellín y el sur del valle del aburrá, Revista Facultad Nacional de Agronomía," Medellín, vol. 61, no. 1, pp. 4422-4431, 2008.

[38] V. Van Hoed, N. De Clercq, C. Echim et al., "Berry seeds: A source of specialty oils with high content of bioactives and nutritional value," Journal of Food Lipids, vol. 16, no. 1, pp. 33-49, 2009.

[39] M. Plessi, D. Bertelli, and A. Albasini, "Distribution of metals and phenolic compounds as a criterion to evaluate variety of berries and related jams," Food Chemistry, vol. 100, no. 1, pp. 419-427, 2007.

[40] S. Talcott, "Chemical components of berry fruits," in Berry Fruit, vol. 20072431 of Food Science and Technology, pp. 51-72, CRC Press, 2007.

[41] U.S. Department of Agriculture (USDA) national nutrient database for standard reference, http://www.nal.usda.gov/fnic/ foodcomp/search/, 2016.

[42] L. J. Solana, Geología Regional y Petrogénesis del vulcanismo silícico de la región circundante a la ciudad de Tulancingo, Tesis. Universidad Autónoma del Estado de Hidalgo, Hidalgo, México, 2012.

[43] F. Famiani, A. Battistelli, S. Moscatello, J. G. Cruz-Castillo, and R. P. Walker, "The organic acids that are accumulated in the flesh of fruits: Occurrence, metabolism and factors affecting their contents - A review," Revista Chapingo, Serie Horticultura, vol. 21, no. 2, pp. 97-128, 2015.

[44] G. Pande and C. C. Akoh, "Organic acids, antioxidant capacity, phenolic content and lipid characterisation of Georgia-grown underutilized fruit crops," Food Chemistry, vol. 120, no. 4, pp. 1067-1075, 2010.

[45] B.-M. Ruiz-Rodríguez, P. Morales, V. Fernández-Ruiz et al., "Valorization of wild strawberry-tree fruits (Arbutus unedo L.) through nutritional assessment and natural production data," Food Research International, vol. 44, no. 5, pp. 1244-1253, 2011. 
[46] P. Morales, I. C. F. R. Ferreira, A. M. Carvalho et al., "Wild edible fruits as a potential source of phytochemicals with capacity to inhibit lipid peroxidation," European Journal of Lipid Science and Technology, vol. 115, no. 2, pp. 176-185, 2013.

[47] Y. Liu, X. Zhang, and Z. Zhao, "Effects of fruit bagging on anthocyanins, sugars, organic acids, and color properties of 'Granny Smith' and 'Golden Delicious' during fruit maturation,' European Food Research and Technology, vol. 236, no. 2, pp. 329339, 2013.

[48] J. Lopez-Bucio, M. F. Nieto-Jacobo, V. Ramírez-Rodríguez, and L. Herrera-Estrella, "Organic acid metabolism in plants: from adaptive physiology to transgenic varieties for cultivation in extreme soils," Journal of Plant Sciences, vol. 160, no. 1, pp. 1-13, 2000.

[49] B. S. Bushman, B. Phillips, T. Isbell, B. Ou, J. M. Crane, and S. J. Knapp, "Chemical composition of caneberry (Rubus spp.) seeds and oils and their antioxidant potential," Journal of Agricultural and Food Chemistry, vol. 52, no. 26, pp. 7982-7987, 2004.

[50] A. Fazio, P. Plastina, J. Meijerink, R. F. Witkamp, and B. Gabriele, "Comparative analyses of seeds of wild fruits of Rubus and Sambucus species from Southern Italy: fatty acid composition of the oil, total phenolic content, antioxidant and anti-inflammatory properties of the methanolic extracts," Food Chemistry, vol. 140, no. 4, pp. 817-824, 2013.

[51] J. L. Donovan, A. S. Meyer, and A. L. Waterhouse, "Phenolic Composition and Antioxidant Activity of Prunes and Prune Juice (Prunus domestica)," Journal of Agricultural and Food Chemistry, vol. 46, no. 4, pp. 1247-1252, 1998.

[52] W.-Y. Huang, H.-C. Zhang, W.-X. Liu, and C.-Y. Li, "Survey of antioxidant capacity and phenolic composition of blueberry, blackberry, and strawberry in Nanjing," Journal of Zhejiang University: Science B (Biomedicine \& Biotechnology), vol. 13, no. 2, pp. 94-102, 2012.

[53] J. Dai, A. Gupte, L. Gates, and R. J. Mumper, "A comprehensive study of anthocyanin-containing extracts from selected blackberry cultivars: Extraction methods, stability, anticancer properties and mechanisms," Food and Chemical Toxicology, vol. 47, no. 4, pp. 837-847, 2009.

[54] A. Patras, N. P. Brunton, S. Da Pieve, and F. Butler, "Impact of high pressure processing on total antioxidant activity, phenolic, ascorbic acid, anthocyanin content and colour of strawberry and blackberry purées," Innovative Food Science \& Emerging Technologies, vol. 10, no. 3, pp. 308-313, 2009.

[55] J. Lee, M. Dossett, and C. E. Finn, "Rubus fruit phenolic research: the good, the bad, and the confusing," Food Chemistry, vol. 130, no. 4, pp. 785-796, 2012.

[56] N. Babbar, H. S. Oberoi, D. S. Uppal, and R. T. Patil, “Total phenolic content and antioxidant capacity of extracts obtained from six important fruit residues," Food Research International, vol. 44, no. 1, pp. 391-396, 2011.

[57] M. Ramić, S. Vidović, Z. Zeković, J. Vladić, A. Cvejin, and B. Pavlić, "Modeling and optimization of ultrasound-assisted extraction of polyphenolic compounds from Aronia melanocarpa by-products from filter-tea factory," Ultrasonics Sonochemistry, vol. 23, pp. 360-368, 2015.

[58] S. Kamiloglu, E. Capanoglu, F. D. Bilen et al., "Bioaccessibility of Polyphenols from Plant-Processing Byproducts of Black Carrot (Daucus carota L.)," Journal of Agricultural and Food Chemistry, vol. 64, no. 12, pp. 2450-2458, 2016.

[59] G.-F. Deng, C. Shen, X.-R. Xu et al., "Potential of fruit wastes as natural resources of bioactive compounds," International Journal of Molecular Sciences, vol. 13, no. 7, pp. 8308-8323, 2012.
[60] D. Huang, B. Ou, and R. L. Prior, "The chemistry behind antioxidant capacity assays," Journal of Agricultural and Food Chemistry, vol. 53, no. 6, pp. 1841-1856, 2005.

[61] V. Roginsky, "Chain-breaking antioxidant activity of natural polyphenols as determined during the chain oxidation of methyl linoleate in Triton X-100 micelles," Archives of Biochemistry and Biophysics, vol. 414, no. 2, pp. 261-270, 2003.

[62] C. A. Rice-Evans, N. J. Miller, and G. Paganga, "Structureantioxidant activity relationships of flavonoids and phenolic acids," Free Radical Biology \& Medicine, vol. 20, no. 7, pp. 933956, 1996.

[63] J. F. Ayala-Zavala, C. Rosas-Domínguez, V. Vega-Vega, and G. A. González-Aguilar, "Antioxidant enrichment and antimicrobial protection of fresh-cut fruits using their own byproducts: Looking for integral exploitation," Journal of Food Science, vol. 75, no. 8, pp. R175-R181, 2010.

[64] F. Figuerola, M. L. Hurtado, A. M. Estévez, I. Chiffelle, and F. Asenjo, "Fibre concentrates from apple pomace and citrus peel as potential fibre sources for food enrichment," Food Chemistry, vol. 91, no. 3, pp. 395-401, 2005.

[65] G. F. E. Valencia, M. M. O. Romßn, and M. M. O. Román, "Caracterizaci $\leq \mathrm{n}$ fisicoqu $\varphi$ mica y funcional de tres concentrados comerciales de fibra dietaria," Vitae (Medellin), vol. 13, no. 2, pp. 54-60, 2006.

[66] M. F. Basanta, M. F. De Escalada Plá, M. D. Raffo, C. A. Stortz, and A. M. Rojas, "Cherry fibers isolated from harvest residues as valuable dietary fiber and functional food ingredients," Journal of Food Engineering, vol. 126, pp. 149-155, 2014.

[67] A. Femenia, A.-C. Lefebvre, J.-Y. Thebaudin, J. A. Robertson, and C.-M. Bourgeois, "Physical and sensory properties of model foods supplemented with cauliflower fiber," Journal of Food Science, vol. 62, no. 4, pp. 635-639, 1997.

[68] R. A. M. Chamorro and E. C. Mamani, "Importancia de la fibra dietética, sus propiedades funcionales en la alimentación humana y en la industria alimentaria," Revista de Investigación en Ciencia y Tecnología de Alimentos, vol. 1, no. 1, p. 17, 2015.

[69] M. M. A. K. Khattak, "Physiological effects of dietary complex carbohydrates and its metabolites role in certain diseases," Pakistan Journal of Nutrition, vol. 1, no. 4, pp. 161-168, 2002.

[70] M. Villarroel, C. Acevedo, E. Yß, E. Biolley, and E. Yáñez, "Propiedades funcionales de la fibra del musgo Sphagnum magellanicum y su utilización en la formulación de productos de panadería," Archivos Latinoamericanos de Nutricion, vol. 53, no. 4, p. 14, 2003.

[71] C. Zhao, M. M. Giusti, M. Malik, M. P. Moyer, and B. A. Magnuson, "Effects of commercial anthocyanin-rich extracts on colonic cancer and nontumorigenic colonic cell growth," Journal of Agricultural and Food Chemistry, vol. 52, no. 20, pp. 6122-6128, 2004.

[72] R. E. Wrolstad, "Anthocyanin pigmentsBioactivity and coloring properties," Journal of Food Science, vol. 69, no. 5, pp. C419C425, 2004.

[73] C. Malien-Aubert, O. Dangles, and M. J. Amiot, "Color stability of commercial anthocyanin-based extracts in relation to the phenolic composition. Protective effects by intra- and intermolecular copigmentation," Journal of Agricultural and Food Chemistry, vol. 49, no. 1, pp. 170-176, 2001.

[74] G. Garzón, "Las antocianinas como colorantes naturales y compuestos bioactivos: revisión," Acta Biológica Colombiana, vol. 13, no. 3, pp. 27-36, 2008. 


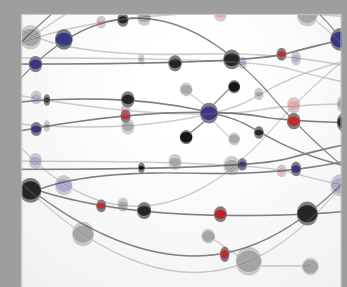

The Scientific World Journal
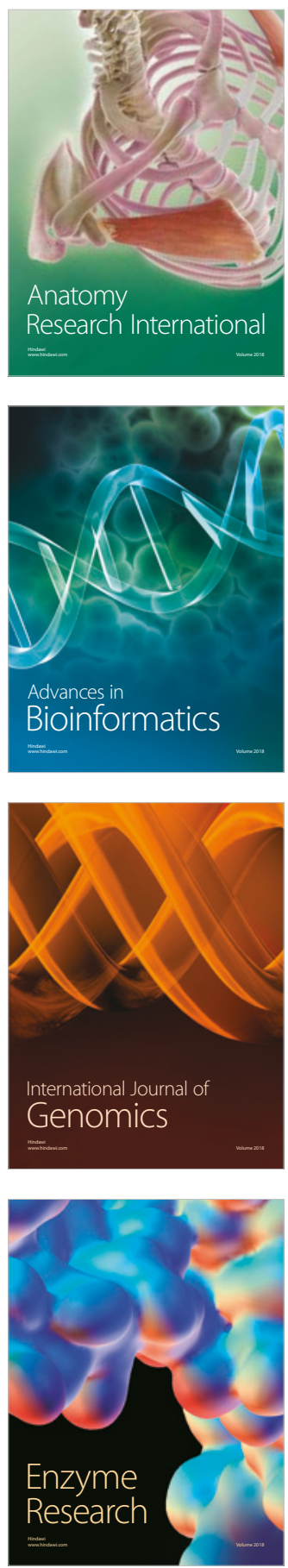
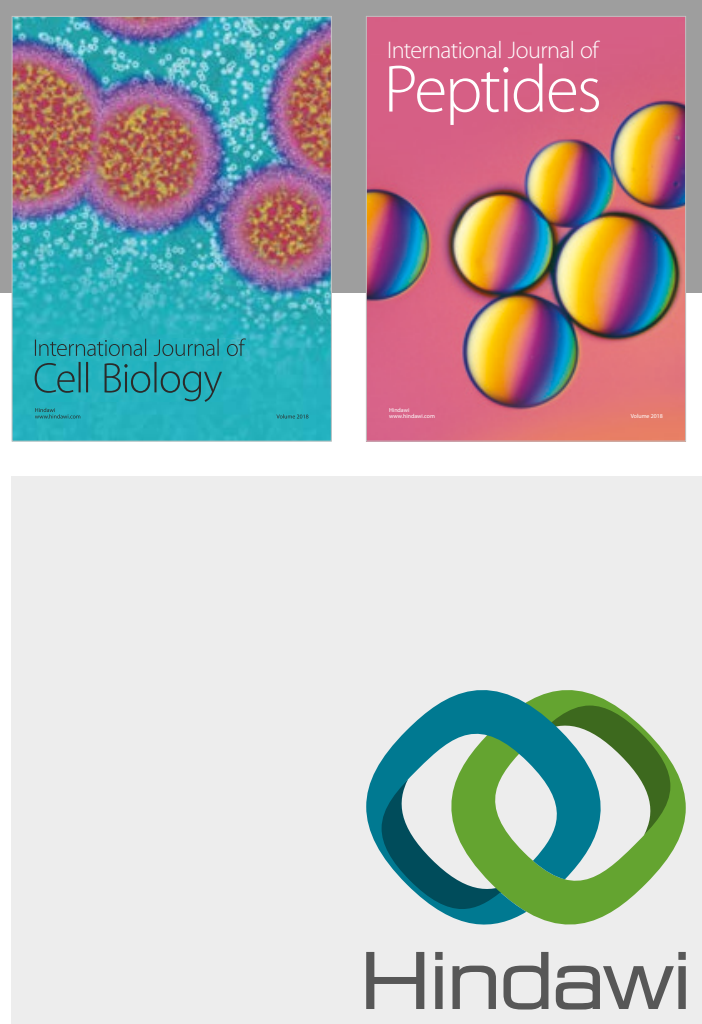

Submit your manuscripts at

www.hindawi.com
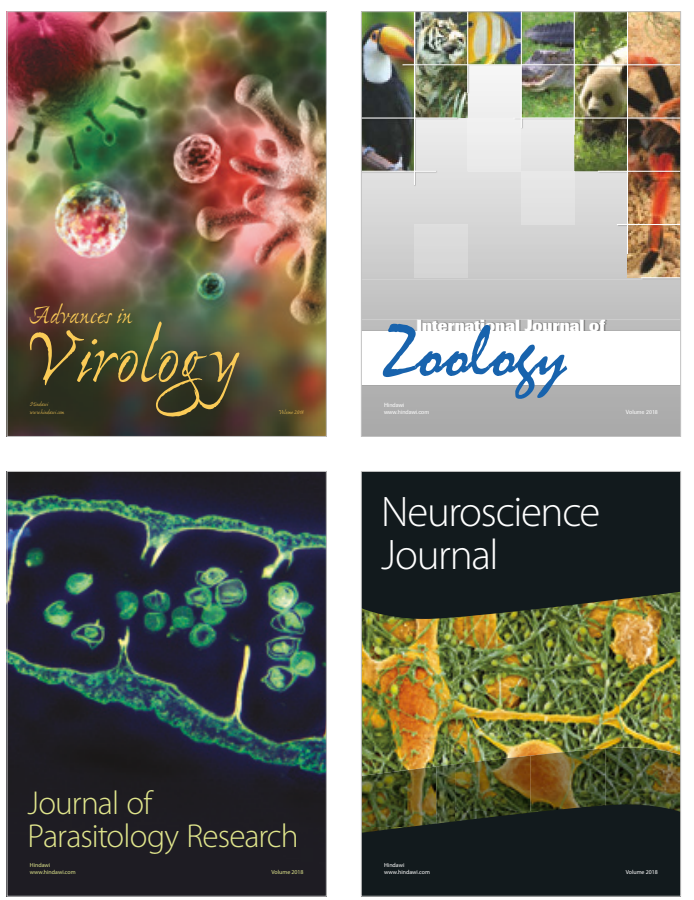
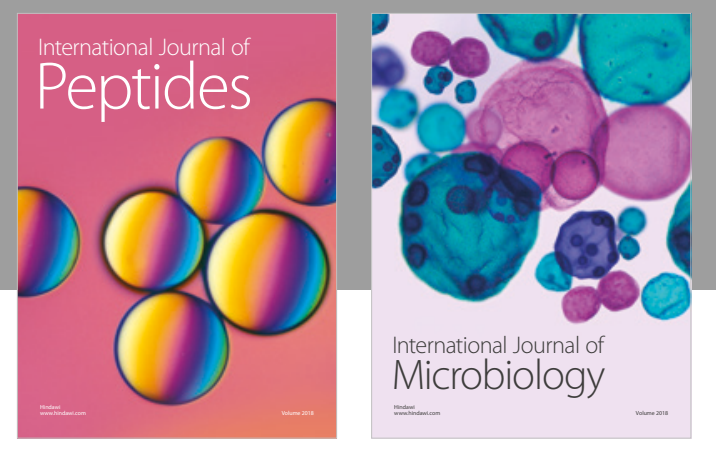

nternational Journal of Microbiology
Journal of
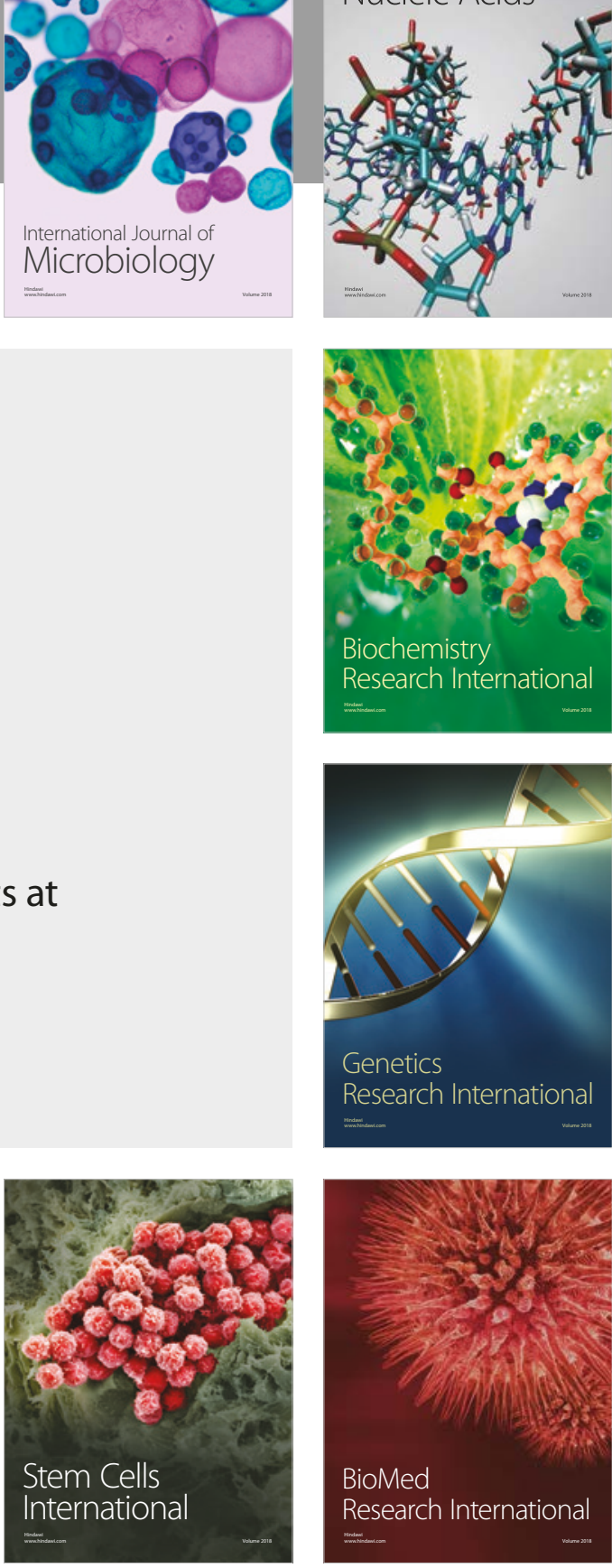
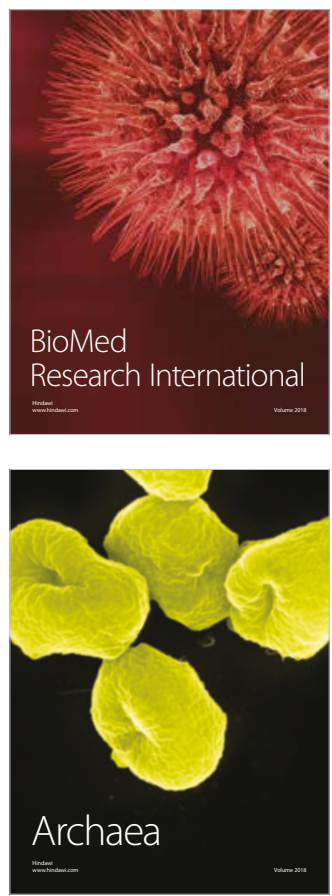